\title{
An Extraaxial Cerebello-Pontine Angle Medulloblastoma in a 56 Year Old Male - A Rare Case Report
}

\author{
Dr. Meghana Chougule ${ }^{1}$, Dr. Santosh Prabhu ${ }^{2}$ \\ ${ }^{1}$ Consulting Pathologist, Shanti Laboratory, Kolhapur, Maharashtra, India \\ ${ }^{2}$ Consulting Neurosurgeon, WIINS, Kolhapur, Maharashtra, India
}

\begin{abstract}
A case of extraaxial cerebello-pontine angle medulloblastoma in a 56 year old male is reported for its unusual location \& age. Medulloblastoma accounts for 20\% of brain tumors arising in childhood Peak incidence occurs between the 5 \& 10 year of life.[1] Cerebellar medulloblastoma is classically seen during childhood, and less than $25 \%$ of these tumors are found in adults below 40 years of age. Rarely, cases are reported above the age of 40 years. Medulloblastoma is very rare in adults and reports of its occurrence worldwide are scarce.
\end{abstract}

Keywords: Medulloblastoma, extra-axial, cerebello-pontine angle, elderly, Synaptophysin

\section{Case Presentation}

A 56-year old male, known case of Hepatitis B had been complaining of severe, periodic headaches and dizziness with ataxic gait. Computed tomography and magnetic resonance imaging of the head showed a diffusely enhancing heterogeneous lesion located in the right cerebello-pontine angle measuring $4.5 \times 3.5 \times 3 \mathrm{~cm}$. (Fig.1)The patient was operated and the tumor was totally excised.

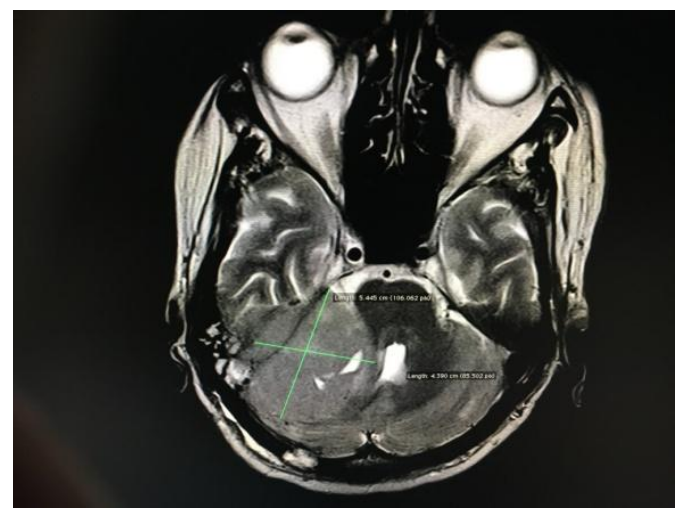

Figure 1: MRI showing tumor of $\mathrm{cp}$ angle

Histopathology showed a densely cellular undifferentiated tumor composed of large, round to oval neoplastic cells arranged in nodules, diffuse sheets, small nests and clusters having high nuclear cytoplasmic ratio with clumped chromatin, containing nucleoli and scanty amount of eosinophilic cytoplasm. Brisk mitotic activity \& apoptosis were also noted. The intervening stroma showed areas of necrosis \& heamorrhages. (Fig.2) Differential diagnosis of small cell blue cell malignant tumor and metastatic small cell carcinoma of lung had to be taken into consideration.

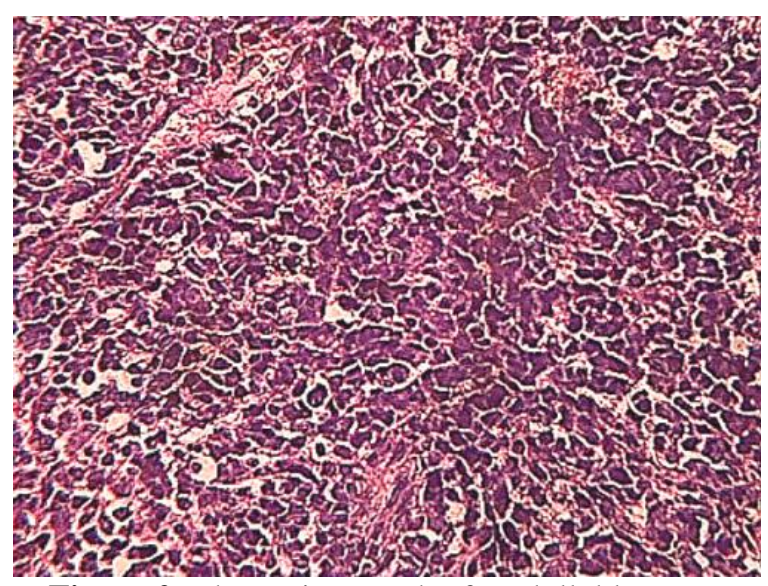

Figure 2: Photomicrograph of medulloblastoma

Immunohistochemistry was performed which showed strong positivity for Synaptophysin (Fig. 3) and high Mib (Ki-67) 22 to25\%. (Fig. 4) LCA, CD34 \& Cytokeratin were negative.

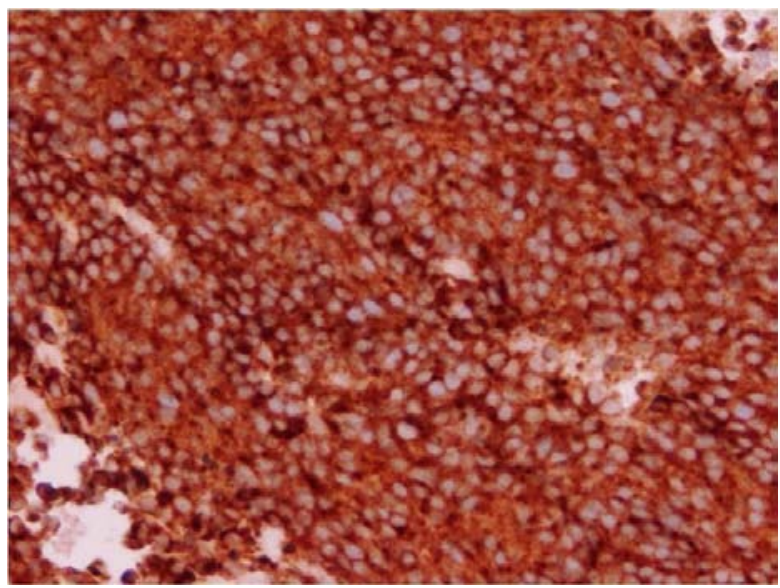

Figure 3: Synaptophysin strongly positive 


\section{International Journal of Science and Research (IJSR) \\ ISSN (Online): 2319-7064 \\ Index Copernicus Value (2013): 6.14 | Impact Factor (2015): 6.391}

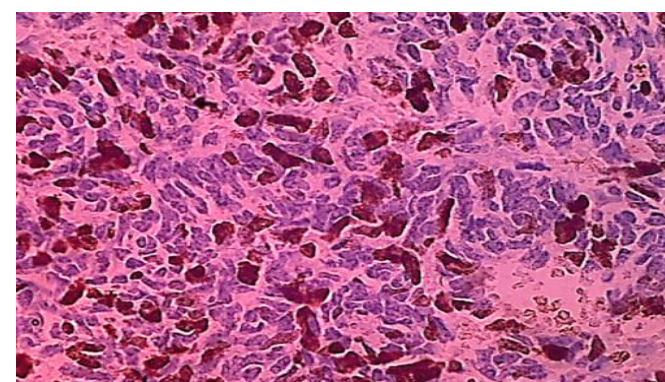

Figure 4: Mib-1 (Ki-67) is 22-25 \%

\section{Discussion}

Medulloblastoma is counted among childhood tumors. Its incidence among adults is low; the annual morbidity rate being approximately 0.05 per 100 000.[1] The most common site for medulloblastoma development is the cerebellar vermis. From this location the tumor penetrates into the flow of cerebro-spinal fluid. Often the tumor surrounds and infiltrates the fourth ventricle, Extension into the subarachnoid space is common, particularly in nodular/desmoplastic medulloblastomas. Spreading along the cerebro-spinal fluid routes, medulloblastoma may become disseminated within the central nervous system in $10-30 \%$ of pediatric patients. Medulloblastomas involving the peripheral cerebellar hemispheres in adults may occasionally appear as extra-axial lesions simulating meningiomas or vestibular nerve schwannomas.[2] Medulloblastoma belongs to the PNET group of tumors that originate from primitive, neuroepithelial cells.

The tumor has two histological variants: classic and desmoplastic. The desmoplastic form is found in $20-40 \%$ of adult cases and in $10 \%$ of pediatric patients.[3-5]

However the following six categories overlapping are descriptive 1) Classical 2) With neuroblastic differentiation 3) With glial or mixed glioneuronal differentiation 4) With nodular/desmoplastic features 5) With extensive nodularity and 6) with anaplasia and or large cell features.

Medulloblastomas are almost always Synaptophysin positive particularly the fibrillary cores of Homer Wright Rossets, perivascular pseudorosettes and pale islands.[6, 7, 8] Some show immunoreactivity for microtubule associated protein, class III beta tubulin. Molecular and cytogenetic study show loss of all or part of chromosome 17p with duplication of and translocation of chromosome 17q.[9,10] Some authors believe that - after comprehensive therapy - the prognosis in medulloblastoma is more favorable in adults than in children.[11] Therapeutic management of medulloblastoma consists of an as-radical-as-possible excision of the tumor mass, followed by irradiation. In children, chemotherapy is also applied, though routine chemotherapy in adult patients is still a matter of controversy in view of the resultant problems in finding a uniform group if patients for clinical trials, and the slightly different course of the disease as compared to children. The mean age of such adult patients is approximately 25 years (22.4-34.1). Cases in patients older than 40 years are very rare. Our patient was 56 years old at the time of diagnosis. The tumor was located in the vermis is often the case in children, although in adults it is more often situated in the cerebellar hemispheres.[4, 5, 11]
Standard management in adults lies in maximally radical surgery with subsequent irradiation. The elevated risks from surgery should however be taken into account in some cases, particularly those involving large tumors. Postoperative complications such as haematoma or cerebrospinal circulation disturbances can affect outcome. Besides, radiotherapy may be postponed owing to additional neurosurgical procedures- haematoma removal, orcerebrospinal fluid shunting. At present, the standard of management, both in older children and in adults, is combined therapy consisting of a maximally radical operation followed by adjuvant irradiation of the entire central nervous system. Irradiation uses doses of up to 3500cGy and the dose to the posterior cranial fossa is subsequently increased, reaching an accumulated dose of 5500cGy.[12]

\section{References}

[1] Ingraham FD, Bailey OT, Barker WF: Medulloblastoma cerebelli: Diagnosis, treatment and survivals, with a report of fifty-six cases. N Engl J Med 1948; 238: 171174.

[2] 2 2.(Ref. Becker RL, Becker AD, Sobel DF(1995) Adult Medulloblastoma: Review of 13 cases with emphasis on MRI. Neuroradiology 37:104-108.)

[3] Marty- Double C, Barneon G: Le medulloblastome de l'adulte (a propas d'une serie de 22 cas). Ann Anat Pathol (Paris) 1974; 19: 189-210.

[4] Kepes JJ, Morantz RA, Dorzab WE: Cerebellar medulloblastoma in a 73-year-old woman. Neurosurgery 1987; 21: 81-83.

[5] Bailey G, Cushing H: Medulloblastoma cerebelli: A common type of midcerebellar glioma in childhood. Arch Neurol 1925; 14: 192-233.

[6] Woodhouse MA, Dayan AD, Burston J, et al. Progressive multifocal leukoencephalopathy: electron microscope study of four cases. Brain 1967;90:863-70.

[7] Shintaku M, Matsumoto R, Sawa H, Nagashima K. Infection with JC virus and possible dysplastic ganglion-like transformation of the cerebral cortical neurons in a case of progressive multifocal leukoencephalopathy. J Neuropathol Exp Neurol 2000;59:921-9.

[8] Willman CL, Busque L, Griffith BB, et al. Langerhans' cell histiocytosis (histiocytosis X)- a clonal proliferative disease. N Engl J Med 1994;331:154-60.

[9] Hair LS, Nuovo G, Powers JM, Sisti MB, Britton CB, Miller JR. Progressive multifocal leukoencephalopathy in patients with human immunodeficiency virus. Hum Pathol 1992;23:663-7.

[10]Breidahl WH, Robbins PD, Ives FJ, Wong G. Intracranial plasma cells granuloma. Neuroradiology 1996;38(Suppl 1):S86-9.

[11] Marty- Double C, Barneon G: Le medulloblastome de l'adulte (a propas d'une serie de 22 cas). Ann Anat Pathol (Paris) 1974; 19: 189-210.

[12] Malgorzata Bolek-Górska1BDEF, Elżbieta KorabChrzanowska2DE, Ryszard Czepko3B: Medulloblastoma in adults. A case presentation and review of the literature; Rep Pract Oncol Radiother, 2006; 11(1): 49-54

\section{Volume 5 Issue 4, April 2016

